\title{
Encyclopedia of Dentistry Research (2 Volume Set)
}

\section{Steven D. Levenstein}

Publisher: Nova Science Publishers, Inc.

Language: English

ISBN: 978-1-62417-491-9

Edition: $1 / \mathrm{e}$

Publish Year: 2012

Pages: 805, illustrated

Price: $\$ 325.00$

The book entitled Encyclopedia of Dentistry Research brings together a wide range of research on the structure of tooth enamel and dental materials used for restoring tooth structure and oral rehabilitation of the stomatognathic system.

In the 20 chapters of the first volume the book discusses about the structure, composition, properties, dental erosion of human enamel, resin composites for post cementation and core buildup, Nickel-Chrome alloys for the preparation of metallic restorations, dental nanocomposites, the evaluation of biomimetic polymeric dental composites, placing implants and alveolar bone and loading distractions for implant rehabilitation.

The second volume has 19 chapters and speaks about oral implantology and chronic periodontitis. With respect to oral implantology, the book presents the following issues: biomechanics of oral implants, considerations of graft materials in maxillary sinus augmentation procedures, onlay block bone grafting, stereolithographic surgical template, overdenture construction of implants

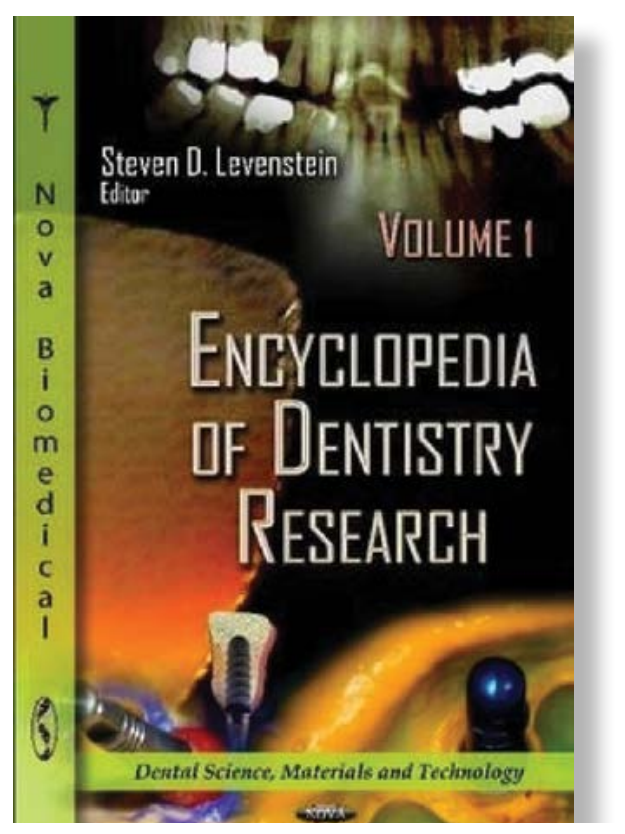

placement using CT scanning techniques and immediate implant loading following extraction. Here are the topics addressed on periodontal disease: risk factors, treatment, prognosis, genetic polymorphisms of chronic periodontal diseases, chronic periodontitis and coronary heart disease, chronic periodontitis and the risk of oral cancer.

In this book, the readers find a wide range of information on restorative dentistry, periodontal disease treatment and various methods and techniques of oral implantology. It is also a book easy to understood and it is also exemplified with numerous images.

https://doi.org/10.25241/stomaeduj.2015.2(2).bookreview.2

The Book Review is drafted in the reviwer's sole wording and illustrates his opinions.

Marian-Vladimir Constantinescu

Department of Prosthetic Dentistry "Carol Davila" University of Medicine and Pharmacy Bucharest, Romania 